\title{
Assessment of Attentional Demand in Patients with Dizziness Using Dual Task Test
}

\author{
Eun Jung Lee, Ah Young Park, Byeong Il Choi, Ji Hyung Kim, \\ Seong Ah Hong, Seon Geum Kim, and Eun Jin Son \\ Department of Otorhinolaryngology, Gangnam Severance Hospital, Yonsei University College of Medicine, Seoul, Korea
}

\author{
어지럼증 환자에서 이중 과제 실험을 이용한 주의 요구의 측정 \\ 이은정 · 박아영 · 최병일 · 김지형 · 홍성아 · 김선금 · 손은진 \\ 연세대학교 의과대학 강남세브란스병원 이비인후과학교실
}

\author{
Received June 16, 2016 \\ Revised January 3, 2017 \\ Accepted January 21, 2017 \\ Address for correspondence \\ Eun Jin Son, MD, PhD \\ Department of Otorhinolaryngology, \\ Gangnam Severance Hospital, \\ Yonsei University \\ College of Medicine, \\ 211 Eonju-ro, Gangnam-gu, \\ Seoul 06273, Korea \\ Tel $+82-2-2019-3460$ \\ Fax $+82-2-3463-4750$ \\ E-mail ejson@yuhs.ac
}

Background and Objectives Even patients with compensated peripheral vestibular dysfunction may report a sense of disequilibrium during daily activities, which often fail conventional vestibular function tests as attentional demand required for postural control may increase in these patients. The study aims to assess the feasibility of dual task test using concurrent cognitive tasks in a modified clinical test of sensory interaction on balance (mCTSIB) to measure increased attentional demand for posture control.

Subjects and Method Nineteen patients suspected with chronic dizziness were recruited by history reviews and physical examinations. Data for center of pressure (COP) variability and mean velocity during $\mathrm{mCTSIB}$ on a force long plate were analyzed, and time taken to react to the auditory stimuli were used to measure the attentional demand required for adequate postural control during platform perturbation.

Results The mean COP range and velocity during mCTSIB were comparable between single and dual task conditions in patients with dizziness. Reaction time (RT) to auditory stimulus of $1 \mathrm{kHz}$ pure tone in patients with chronic dizziness was also comparable to normal subjects. Interestingly, there was a tendency for increased RT in patients with documented caloric weakness, suggesting that attentional demand is increased in these patients.

Conclusion RT of dual task tests using auditory stimuli during mCTSIB may provide additional information about increased attentional demand for postural control in patients with vestibular dysfunction.

Korean J Otorhinolaryngol-Head Neck Surg 2017;60(5):215-21

Key Words Attention - Posture - Reaction time - Task performance and analysis · Vestibular diseases.

\section{Introduction}

Sensory input from visual, vestibular and somatosensory systems provide fundamental information for balance and posture control in humans. Posture control is coordinated by

This is an Open Access article distributed under the terms of the Creative Commons Attribution Non-Commercial License (http://creativecommons.org/licenses/by-nc/4.0) which permits unrestricted non-commercial use, distribution, and reproduction in any medium, provided the original work is properly cited. the central nervous system that integrates the sensory information and relays appropriate motor control. Notably, cognitive functions such as attention are required in posture control. ${ }^{1,2)}$

During the acute phase of peripheral vestibular dysfunction, the patients suffer severe symptoms of vertigo and deficits in posture control, highlighted by lateropulsion and difficulty in performing Romberg tests. In compensated phase, most of the patients are able to perform daily activities with- 
out much distress even though vestibular hypofunction may persists as evidenced by caloric test, rotational chair test or vestibular evoked myogenic potential tests. However, a portion of patients experienced persistent vestibular symptoms that hinder their return to the daily routine. In these patients, while the subjective measures of the vestibular symptoms reflect the burden on daily activities, the results of dynamic posturography testing are often within normal range and their frustration may be overlooked by the physicians as mere emotional or psychological.

The ability to maintain an erect posture commands complex sensory-motor and cognitive processes. ${ }^{3)}$ Attentional demand for maintaining a given posture is increased in various conditions including normal aging, after stroke and musculoskeletal disorders. ${ }^{3-7)}$ Increased attentional demand has been correlated with increased fall risks. ${ }^{8,9)}$ Based on these studies, we hypothesized that some patients with "compensated" vestibulopathy experience vestibular symptoms due to increased attentional demand for posture control in everyday life situations where the attentional must be allocated for execution of multiple tasks as well as balance control.

In this study, we aimed to assess the feasibility of dual task test using concurrent cognitive task to the modified clinical test of sensory interaction on balance (mCTSIB) to measure the increased attentional demand for posture control in patients with persistent vertigo symptoms.

\section{Subjects and Method}

\section{Subjects}

Eight healthy controls (M:F=2:6, mean age 27.4 years, standard deviation 2.9) were included in the study (Table 1). They reported no vestibular symptom or had been clinically diagnosed with any vestibular disorders. All underwent a complete medical examination and only individuals free from known muscular, neurological or cardiovascular deficits took part in the study. Nineteen patients with chronic dizziness (M:F=9:10, age 52.6 \pm 16.5 years) were also recruited (Table 1). Peripheral vestibular dysfunction was diagnosed from the review of patients' history, physical examinations and vestibular test results: the clinical diagnoses included compensated vestibular neuritis, persistent dizziness after benign paroxysmal positional vertigo (BPPV), and chronic non-specific dizziness. Patients with previous attack(s) of BPPV were included only when they reported persistent dizziness symptoms for longer than one month. The patient group was subdivided according to presence of canal paresis (CP) on caloric testing ( $\mathrm{CP}>22 \%$ considered abnormal). Using $\mathrm{CP}$, the sensitivity for this test alone was $12-18 \%$ and its specificity was $93-100 \%{ }^{10)}$ The Institutional Review Board for the author's affiliated University College of Medicine and author's hospital approved this study.

\section{Study protocol}

mCTSIB was performed as the single task test on an Equitest $^{\circledR}$ (NeuroCom International Inc., Portland, OR, USA) in accordance with the NeuroCom instruction manual. ${ }^{11)}$ Participants were instructed to maintain their posture as stable as possible during 4 different conditions of mCTSIB: standing on firm surface with eyes open (Firm-EO), on firm surface with eyes closed (Firm-EC), on foam surface with eyes open (FoamEO), and on foam surface with eyes closed (Foam-EC). Three repetitions were done for each of the four test conditions. We measured the center of pressure (COP) variability during

Table 1. Clinical characteristics

\begin{tabular}{|c|c|c|c|c|}
\hline \multirow[b]{2}{*}{ Variables } & \multirow{2}{*}{$\begin{array}{c}\text { Healthy } \\
\text { subjects }(n=8)\end{array}$} & \multicolumn{3}{|c|}{ Patients with chronic dizziness $(n=19)$} \\
\hline & & All patients & $\begin{array}{c}\text { With canal } \\
\text { paresis }(n=6)\end{array}$ & $\begin{array}{l}\text { Without canal } \\
\text { paresis }(n=13)\end{array}$ \\
\hline$M: F$ & $2: 6$ & $9: 10$ & $3: 3$ & $6: 7$ \\
\hline Age (mean $\pm S D$, years) & $27.4 \pm 2.9$ & $52.6 \pm 16.5$ & $60.5 \pm 14.3$ & $49.0 \pm 16.6$ \\
\hline Height (mean $\pm S D, c m)$ & $165.9 \pm 16.0$ & $164.7 \pm 10.0$ & $161.5 \pm 10.6$ & $166.2 \pm 9.7$ \\
\hline $\begin{array}{l}\text { Clinical diagnosis } \\
\text { (number of patients) }\end{array}$ & & $\begin{array}{l}\text { Vestibular neuritis (12) } \\
\text { BPPV (3) } \\
\text { Non-specific dizziness (4) }\end{array}$ & $\begin{array}{l}\text { Vestibular neuritis (4) } \\
\text { BPPV (1) } \\
\text { Non-specific dizziness (1) }\end{array}$ & $\begin{array}{l}\text { Vestibular neuritis (8) } \\
\text { BPPV (2) } \\
\text { Non-specific dizziness (3) }\end{array}$ \\
\hline $\begin{array}{l}\text { Duration of dizziness } \\
\text { symptoms (mean } \pm S D \text {, } \\
\text { range, months) }\end{array}$ & & $9.6 \pm 26.2(1-120)$ & $20.1 \pm 44.2(1-120)$ & $4.0 \pm 3.7(1-10)$ \\
\hline $\begin{array}{l}\text { Canal paresis on caloric } \\
\text { test (mean } \pm \text { SD, \%) }\end{array}$ & & $24.0 \pm 0.27$ & $56.2 \pm 0.27$ & $9.0 \pm 0.05$ \\
\hline
\end{tabular}

BPPV: benign paroxysmal positional vertigo, SD: standard deviation 
mCTSIB on a force long plate. Mean COP sway velocity was calculated as the average of the three trials and composite sway scores is calculated as the mean sway velocity averaged over the twelve trials.

Dual task test using the auditory reaction time (RT) task was performed in order to assess attentional demand required for posture control (Fig. 1). The participants were instructed to respond to auditory stimulus as quickly as possible by pressing a button on a hand-held device, and the RT, the elapsed time between the presentation of a sensory stimulus and the subsequent behavioral response, was measured. Twelve auditory stimuli (sound frequency of $1000 \mathrm{~Hz}$ ) were presented through a loud speaker located $1 \mathrm{~m}$ behind the participant at random intervals of 0.8 to $2 \mathrm{sec}$ by steps of $0.2 \mathrm{sec}$. The RT measurements to the first and last stimuli were excluded. No instruction was given regarding the priority between the pos- tural and RT tasks during dual task conditions. Mean COP sway velocity and RT data acquired from the dual task tests were compared to single-task baseline data.

\section{Statistical analysis}

All data are reported as mean values \pm standard deviation. Two-way repeated-measures analyses of variance were applied to the dependent variables, depending on the conditions, to investigate differences between groups and/or conditions.

\section{Results}

\section{Mean COP sway velocity during single vs. dual task test}

Mean COP sway velocity scores were analyzed for the four conditions (Firm-EO, Firm-EC, Foam-EO, and Foam-EC) during single task test of mCTSIB and dual task test of mCTSIB
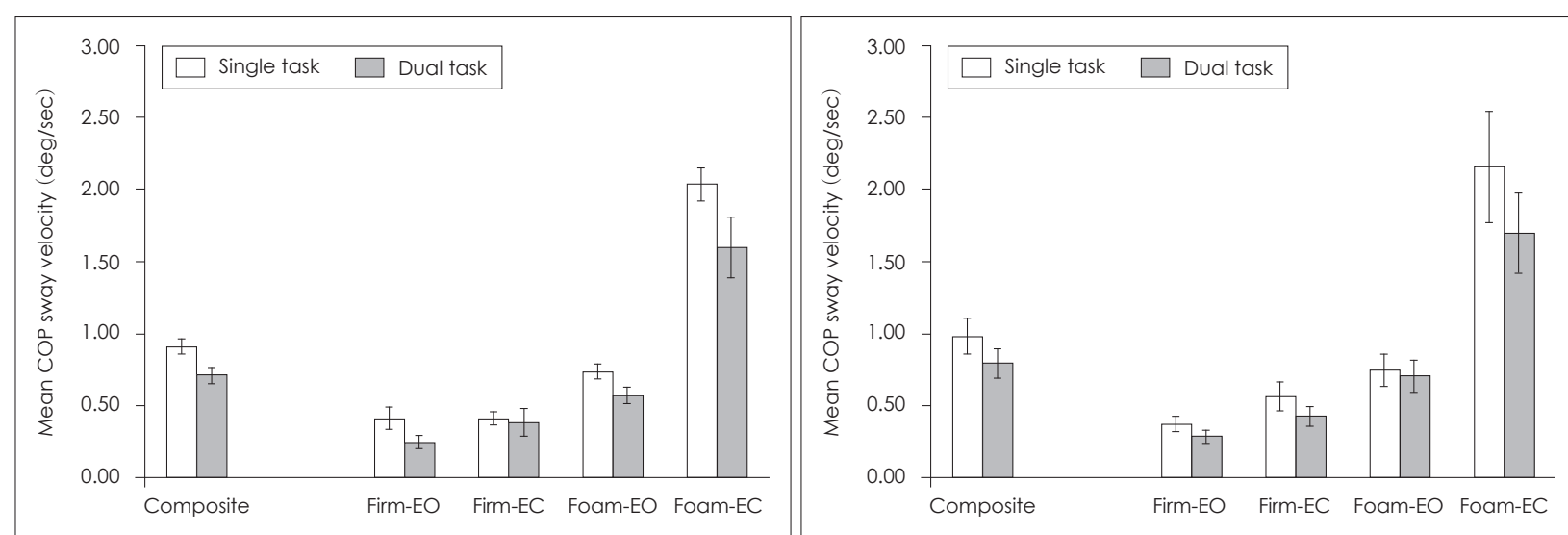

A

Test conditions

B

Test conditions
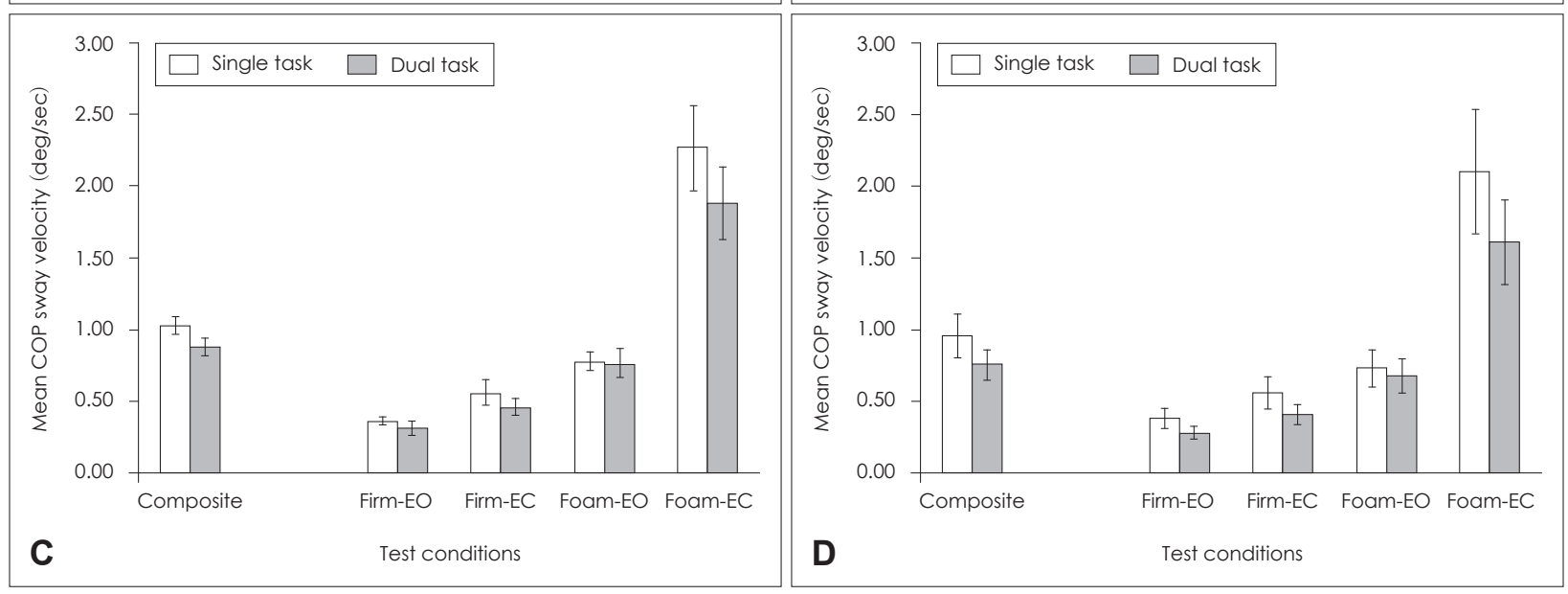

Fig. 1. Mean COP way velocity during single and dual task tests. Mean COP sway velocity scores for each of 4 mCTSIB conditions and composite scores were compared for healthy subjects during single and dual task tests. The mean COP sway velocity tended to decrease during dual task conditions in healthy subjects $(A)$. The mean COP sway velocity scores were similar for patients with chronic dizziness compared to those of the healthy subjects (B). Again, the mean COP sway velocity scores were similar between the patient groups with canal paresis (C) and without canal paresis (D). Firm-EO: firm surface with eyes open, Firm-EC: firm surface with eyes closed, Foam-EO: foam surface with eyes open, Foam-EC: foam surface with eyes closed, COP: center of pressure, mCTSIB: modified clinical test of sensory interaction on balance. 
and auditory RT task (Fig. 1). Overall, mean COP sway velocity increased with increased difficulty in each condition as expected, in the order of Firm-EO, Firm-EC, Foam-EO, to FoamEC. In healthy subjects, the mean COP sway velocity was not significantly different dual task compared to single-task test, in all four conditions (Fig. 1A). In all patients with chronic dizziness, the mean center of gravity (COG) sway velocity scores showed similar patterns to those of the healthy subjects (Fig. 1B), no significant difference was found between dual task and single task tests. In chronic dizziness patients with $\mathrm{CP}$, the mean COP sway velocity scores did not differ significantly between single task and dual task tests (Fig. 1C). Likewise, in chronic dizziness patients without $\mathrm{CP}$, the mean $\mathrm{COP}$ sway velocity scores were not significantly different (Fig. 1D).

Next, we compared whether mean COP sway velocity differed among healthy subjects and subgroups of patients with chronic dizziness. In single task tests, there was no statistically significant difference in mean COP sway velocity when we compared healthy subjects vs. all patients with chronic dizziness, healthy subjects vs. patients with $\mathrm{CP}$, healthy subjects vs. patients without paresis, or patients with
CP vs. without CP (Table 2). In dual task tests, there was no statistically significant difference in mean COP sway velocity among healthy subjects and subgroups of patients with chronic dizziness (Table 3).

\section{Reaction time}

In order to assess the attentional demand during posture control in the four mCTSIB conditions, RTs to auditory stimuli were measured (Fig. 2). When only the RT task was given, the RT was $315.0 \pm 12.1 \mathrm{msec}$ for the healthy subjects and $307.3 \pm$ $31.8 \mathrm{msec}$ for patients with chronic dizziness. RT measurements from dual task tests were similar for the healthy subjects and patients with chronic dizziness in all condition (Fig. 2A). However, when we compared the RT measurements between the patient groups with and without CP in each test condition, RT to auditory stimuli was increased in patients with $\mathrm{CP}$, although statistically not significant. The trend suggests that the patients with documented $\mathrm{CP}$ required more attention to maintain posture during dual task test (Fig. 2B).

Next, we compared RT measurements during dual task test among healthy subjects and subgroups of patients with

Table 2. Comparison of COP sway velocity during mCTSIB test in single-task condition among patients with chronic dizziness and healthy subjects

\begin{tabular}{lcccc}
\hline & Healthy subjects, & \multicolumn{2}{c}{ Patients with chronic dizziness } \\
\cline { 3 - 5 } & mean \pm SD & $\begin{array}{c}\text { All patients, } \\
\text { mean } \pm \text { SD }\end{array}$ & $\begin{array}{c}\text { With canal paresis, } \\
\text { mean } \pm \text { SD }\end{array}$ & $\begin{array}{c}\text { Without canal paresis, } \\
\text { mean } \pm \text { SD }\end{array}$ \\
\hline Composite score & $0.90 \pm 0.10$ & $0.97 \pm 0.19$ & $1.03 \pm 0.12$ & $0.95 \pm 0.30$ \\
Firm-EO & $0.41 \pm 0.17$ & $0.37 \pm 0.11$ & $0.37 \pm 0.05$ & $0.38 \pm 0.13$ \\
Firm-EC & $0.41 \pm 0.11$ & $0.56 \pm 0.18$ & $0.57 \pm 0.18$ & $0.56 \pm 0.23$ \\
Foam-EO & $0.71 \pm 0.09$ & $0.73 \pm 0.19$ & $0.78 \pm 0.13$ & $0.73 \pm 0.26$ \\
Foam-EC & $2.03 \pm 0.24$ & $2.14 \pm 0.69$ & $2.27 \pm 0.59$ & $2.10 \pm 0.87$ \\
p-value & - & $0.73^{*}$ & $0.39^{*}$ & $0.32^{*}, 0.99 \dagger$
\end{tabular}

*compared to healthy subjects, ${ }^{\dagger}$ compared to patients with canal paresis. SD: standard deviation, Firm-EO: firm surface with eyes open, Firm-EC: firm surface with eyes closed, Foam-EO: foam surface with eyes open, Foam-EC: foam surface with eyes closed, COP: center of pressure, MCTSIB: modified clinical test of sensory interaction on balance

Table 3. Comparison of COP sway velocity during mCTSIB test in dual-task condition among patients with chronic dizziness and healthy subjects

\begin{tabular}{lcccc} 
& Healthy subjects, & \multicolumn{3}{c}{ Patients with chronic dizziness } \\
\cline { 3 - 5 } & mean \pm SD & $\begin{array}{c}\text { All patients, } \\
\text { mean } \pm \text { SD }\end{array}$ & $\begin{array}{c}\text { With canal paresis, } \\
\text { mean } \pm \text { SD }\end{array}$ & $\begin{array}{c}\text { Without canal paresis, } \\
\text { mean } \pm \text { SD }\end{array}$ \\
\hline Composite score & $0.71 \pm 0.07$ & $0.79 \pm 0.16$ & $0.88 \pm 0.12$ & $0.75 \pm 0.22$ \\
Firm-EO & $0.24 \pm 0.05$ & $0.29 \pm 0.09$ & $0.32 \pm 0.10$ & $0.28 \pm 0.08$ \\
Firm-EC & $0.40 \pm 0.12$ & $0.42 \pm 0.11$ & $0.47 \pm 0.12$ & $0.41 \pm 0.14$ \\
Foam-EO & $0.57 \pm 0.08$ & $0.69 \pm 0.21$ & $0.77 \pm 0.20$ & $0.68 \pm 0.24$ \\
Foam-EC & $1.60 \pm 0.27$ & $1.68 \pm 0.48$ & $1.88 \pm 0.51$ & $1.61 \pm 0.58$ \\
p-value & - & $0.09^{*}$ & $0.29^{*}$ & $0.57^{*}, 0.52^{\dagger}$
\end{tabular}

*compared to healthy subjects, ${ }^{\dagger}$ compared to patients with canal paresis. SD: standard deviation, Firm-EO: firm surface with eyes open, Firm-EC: firm surface with eyes closed, Foam-EO: foam surface with eyes open, Foam-EC: foam surface with eyes closed, COP: center of pressure, mCTSIB: modified clinical test of sensory interaction on balance 

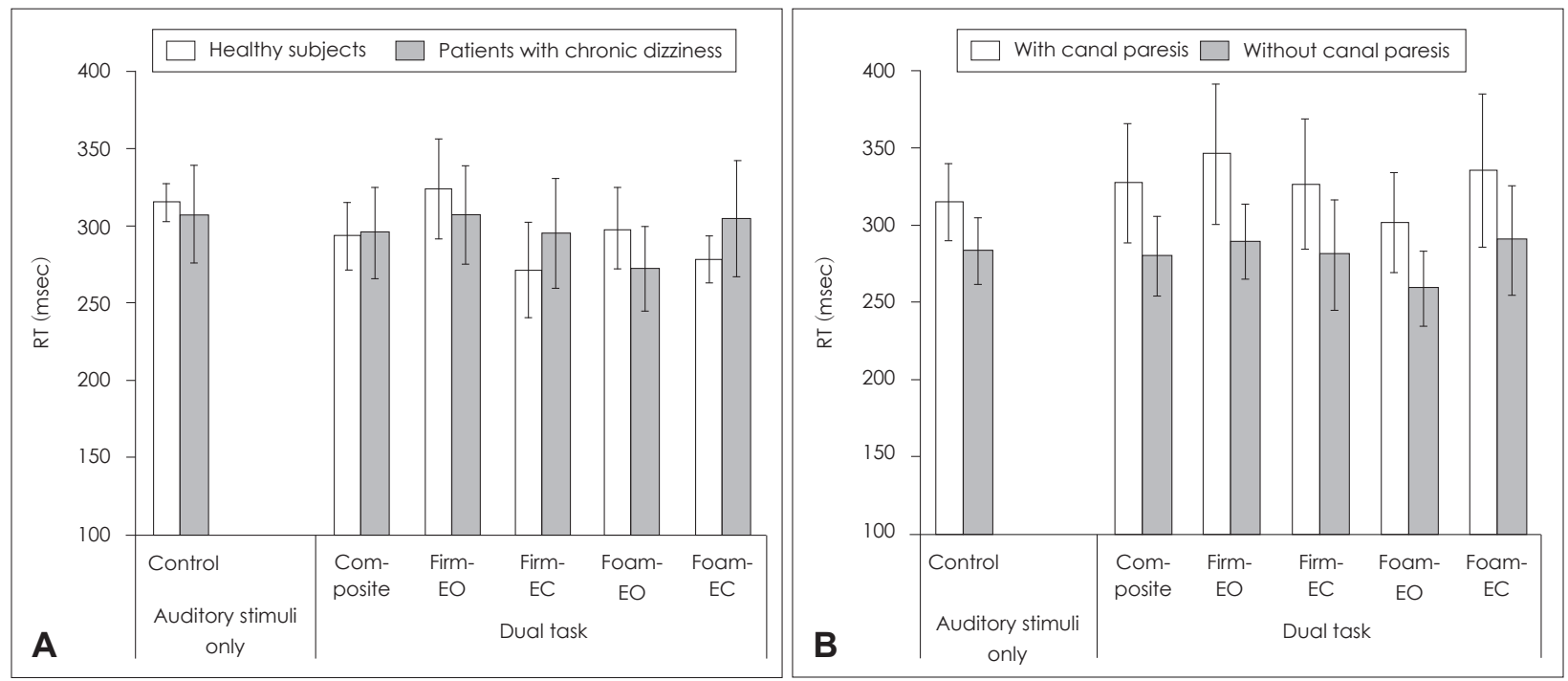

Fig. 2. Reaction time (RT) measurements during dual task test. RT measurements were compared between healthy subjects and patients with chronic dizziness. RT did not differ significantly between the two groups during single RT test or dual task conditions (A). Interestingly, RT measurements were increased in patients with canal paresis when compared to patients without canal paresis (B). FirmEO: firm surface with eyes open, Firm-EC: firm surface with eyes closed, Foam-EO: foam surface with eyes open, Foam-EC: foam surface with eyes closed.

Table 4. Comparison of RT in dual-task condition among patients with chronic dizziness and healthy subjects

\begin{tabular}{|c|c|c|c|c|}
\hline & \multirow{2}{*}{$\begin{array}{l}\text { Healthy subjects, } \\
\text { mean } \pm S D\end{array}$} & \multicolumn{3}{|c|}{ Patients with chronic dizziness } \\
\hline & & $\begin{array}{l}\text { All patients, } \\
\text { mean } \pm S D\end{array}$ & $\begin{array}{c}\text { With canal paresis, } \\
\text { mean } \pm S D\end{array}$ & $\begin{array}{c}\text { Without canal paresis, } \\
\text { mean } \pm \text { SD }\end{array}$ \\
\hline $\mathrm{RT}$ (msec) & $293.0 \pm 43.5$ & $295.0 \pm 59.2$ & $327.4 \pm 76.4$ & $280.0 \pm 45.4$ \\
\hline$p$-value & - & $0.26^{*}$ & $0.05^{*}$ & $0.76^{*}, 0.01^{\dagger}$ \\
\hline
\end{tabular}

* compared to healthy subjects, ${ }^{\dagger}$ compared to patients with canal paresis. SD: standard deviation, RT: reaction time

chronic dizziness (Table 4). There was no statistically significant difference in RT when we compared healthy subjects vs. all patients with chronic dizziness, healthy subjects vs. patients with $\mathrm{CP}$, or healthy subjects vs. patients without paresis. However, RT was statistically significantly increased in chronic dizziness patients with CP compared to patients without CP $(p=0.01)$. Considering that the mean age was older in the group of patients with $\mathrm{CP}$, this finding may reflect increased RT with aging, rather than contribution of $\mathrm{CP}$.

\section{Discussion}

Integration of multi-sensory input is required for maintenance of posture control. Posture and balance control is challenged in many situations during everyday life. For example, crossing the street is comprised of a number of tasks, such as stopping and maintaining posture, head turning and surveillance of possible danger, initiation of movement and walking at appropriate speed. Patients with acute vestibulopathy suffer from severe vertigo and imbalance and the symptoms usu- ally subside as the vestibular loss is compensated. ${ }^{12)}$ However, some patients with compensated or minimal vestibular hypofunction complain of subjective disequilibrium or sensation of imbalance, as well as easy fatigue during their daily routine. We hypothesized that such symptoms may be due to increased attentional demand.

Dynamic posturography and MCTSIB are useful tools to evaluate the functional status of balance and posture control. However, many patients with normal test results may still have balance problems. Various modifications of balance tests have been explored to investigate balance problems not readily evident from conventional balance tests. ${ }^{13-15)}$ Attentional demand can be measured by dual task paradigm. Attention is allocated between maintaining posture and performing the additional cognitive task. It has been reported that attentional demand is increased in elderly patients, after stroke and other disorders. $^{3-7)}$

In our study, we measured the RT to auditory stimulus as a measurement of attentional demand. In normal subjects, RT to auditory stimulus was not prolonged in more challenging 
situations, such as eye closure or standing on foam. The results showed a trend toward prolonged RT in patients with chronic dizziness and balance symptoms compared to healthy subjects, although not statistically significant. The trend may reflect increased attentional demand required for posture control takes up capacity for prompt response in the additional task. It is possible that in our study group, the additional task of responding to the auditory task was too easy to have significant effect on attentional reallocation. However, the study by Jehu, et al. ${ }^{16)}$ showed that addition of cognitive RT task improved posture control, possibly because the postural stability helped the subjects to perform the cognitive RT task. Futures studies are needed to clarify the interaction between the posture control and RT tasks, using various cognitive RT tasks.

It is noteworthy that the COP sway was decreased during dual task situations compared to during single task situation of standing still, both in healthy subjects and patients with chronic dizziness. Previous studies also report better posture control when attention focus is removed from internal focus during quiet stance and sports activities. ${ }^{17,18)}$ A recent study showed that prioritizing attention to a RT task and away from the posture control actually improved postural stability. ${ }^{16)}$ Jehu, et al. ${ }^{16)}$ concluded that when the secondary RT task was complex and required more attentional demand, the subjects may have adapted stiffening strategy that resulted in better posture control. Our results may be explained in a similar manner, suggesting that the subjects unknowingly prioritized the secondary RT task, even though they were not instructed to prioritize the RT task.

During dual task tests, COP sway velocity showed tendency to increase in difficult circumstance such as Foam-EC. This change in COP sway velocity can be explained due to increased difficulty in maintaining posture with more perturbations in sensory inputs. On the other hand, RT measurements were not increased as we have expected. Since RT measurements are used to investigate increased attentional demand for posture control in more difficult conditions, our results might indicate that RT to auditory stimuli is not significantly affected by postural instability in the test conditions. Since RT is an analysis of sensory and neuromotor function that encompasses stimulus recognition and processing, followed by the initiation of a neuromotor response, the RT to auditory stimuli might be rapid and easily adaptive during four test conditions. Another possible assessment tool is to utilize more complex cognitive tasks to measure attentional demand during posture control.
Limitations of this study include the heterogeneity of the patient population. Some patients suffered chronic dizziness symptoms due to insufficient compensation after acute vestibulopathy, and some were diagnosed as chronic non-specific dizziness after neurologic and vestibular testing. Also included are some patients who reported a history of an episodic or recurrent attack of BPPV, after which they experienced prolonged dizziness symptoms. No nystagmus was observed from physical examinations, and subjective dizziness symptoms were chronic in nature. Since the dual task test attempted to investigate whether attentional demand was included in patients with chronic symptoms, these patients were also enrolled. Further studies are needed to investigate whether increased attentional demand is responsible for chronic dizziness symptoms in specific vestibular disorders. Another remaining question is the possibility that attentional demand is increased only after protracted course of vestibular diseases. In such case, dual task test results may change over the disease course. Future studies should be directed to investigate contribution of increased attentional demand in dizziness symptoms at different duration of disease.

The various factors such as sex, age, health of status, and academic background may affect the attentional demand as mentioned above. ${ }^{19)}$ The RT is shortest in twenties, and generally shows a tendency to increase with age. Also, shorter RT was generally reported in male, better status of health, higher academic background. ${ }^{19)}$ Although our analysis could not include all variables such as age, sex and education status, it is noteworthy that the RT was not significantly increased in patient with chronic dizziness, when considering the fact that the age of healthy subject without dizziness was younger than that of patient with chronic dizziness. When we compared RT during dual task tests among normal healthy subjects and subgroups of chronic dizziness, it was significantly increased in patients with CP, compared to patients without CP. Although the increased RT does show that attentional demand is increased in these patients, it remains cautious to assume that the increased attentional demand solely reflects the contribution of vestibular deficit. Most importantly, the mean age is older in patients with $\mathrm{CP}(\mathrm{n}=6$, mean age $60.5 \pm 14.3)$ than patients without CP ( $n=13$, mean age $49.0 \pm 16.6)$. Since dual task test using auditory stimuli is not designed to discern between factors that may contribute to increased attentional demand, further studies are warranted to included patients in various age groups to explore the effects of aging.

In summary, dual task tests using additional auditory RT 
stimulus during mCTSIB may provide additional information about increased attentional demand for postural control in patients with chronic dizziness and imbalance symptoms.

\section{Acknowledgments}

This work is supported by the Basic Science Research Program through the National Research Foundation of Korea (NRF) funded by the Ministry of Education (No. 2013R1A1A2007622 to E.J.S.).

\section{REFERENCES}

1) Fraizer EV, Mitra S. Methodological and interpretive issues in posture-cognition dual-tasking in upright stance. Gait Posture 2008; 27(2):271-9.

2) Riley MA, Baker AA, Schmit JM. Inverse relation between postural variability and difficulty of a concurrent short-term memory task. Brain Res Bull 2003;62(3):191-5.

3) Brown LA, Sleik RJ, Winder TR. Attentional demands for static postural control after stroke. Arch Phys Med Rehabil 2002;83(12): $1732-5$.

4) Granacher U, Wolf I, Wehrle A, Bridenbaugh S, Kressig RW. Effects of muscle fatigue on gait characteristics under single and dual-task conditions in young and older adults. J Neuroeng Rehabil 2010;7:56.

5) Mazaheri M, Salavati M, Negahban H, Sanjari MA, Parnianpour M. Postural sway in low back pain: effects of dual tasks. Gait Posture 2010;31(1):116-21.

6) Mignardot JB, Olivier I, Promayon E, Nougier V. Obesity impact on the attentional cost for controlling posture. PLoS One 2010;5(12): e14387.

7) Schoch B, Hogan A, Gizewski ER, Timmann D, Konczak J. Balance control in sitting and standing in children and young adults with benign cerebellar tumors. Cerebellum 2010;9(3):324-35.

8) Gage WH, Sleik RJ, Polych MA, McKenzie NC, Brown LA. The allocation of attention during locomotion is altered by anxiety. Exp
Brain Res 2003;150(3):385-94.

9) Tucker MG, Kavanagh JJ, Morrison S, Barrett RS. Voluntary sway and rapid orthogonal transitions of voluntary sway in young adults, and low and high fall-risk older adults. Clin Biomech (Bristol, Avon) 2009;24(8):597-605.

10) Jongkees LBW. Value of the caloric test of the labyrinth. Arch Otolaryngol 1948;48:402-17.

11) Rehabilitation Measures Database. Modified clinical test of sensory interaction on balance [cited 2017 Mar 28]. Available from: http:// www.rehabmeasures.org/Lists/RehabMeasures/DispForm. aspx?ID=897.

12) Strupp M, Brandt T. Peripheral vestibular disorders. Curr Opin Neurol 2013;26(1):81-9.

13) Hong SM, Lee HJ, Lee B, Park SK, Hong SK, Park IS, et al. Influence of vestibular disease on psychological distress: a multicenter study. Otolaryngol Head Neck Surg 2013;148(5):810-4.

14) Honaker JA, Converse CM, Shepard NT. Modified head shake computerized dynamic posturography. Am J Audiol 2009;18(2): 108-13.

15) Mishra A, Davis S, Speers R, Shepard NT. Head shake computerized dynamic posturography in peripheral vestibular lesions. Am J Audiol 2009;18(1):53-9.

16) Jehu DA, Desponts A, Paquet N, Lajoie Y. Prioritizing attention on a reaction time task improves postural control and reaction time. Int J Neurosci 2015;125(2):100-6.

17) Nafati G, Vuillerme N. Decreasing internal focus of attention improves postural control during quiet standing in young healthy adults. Res Q Exerc Sport 2011;82(4):634-43.

18) Wulf G, Mercer J, McNevin N, Guadagnoli MA. Reciprocal influences of attentional focus on postural and suprapostural task performance. J Mot Behav 2004;36(2):189-99.

19) Tun PA, Lachman ME. Age differences in reaction time and attention in a national telephone sample of adults: education, sex, and task complexity matter. Dev Psychol 2008;44(5):1421-9. 